\title{
Correlation between general health knowledge and sanitation improvements: evidence from rural China
}

\author{
Li Huang ${ }^{1}$, Meijun Qiu (iD) and Mi Zhou iD ${ }^{1 凶}$
}

\begin{abstract}
A lack of access to sanitation not only has negative effects on the environment but also results in increased prevalence of disease and adversely affects health outcomes. This paper uses data from a survey in Liaoning Province in China to examine the relationship between general health knowledge and improved sanitation facility access. It also explores the effects of work experience and government subsidies on toilet renovation. Using Logit Regression and Duration Analysis, our results show that general health knowledge had a significant positive correlation with flush toilet use and a significant negative correlation with the average duration of traditional latrine pits use. The results of heterogeneity analysis show that work experience in cities can expand farmers' horizons, which increases their general health knowledge. However, per capita government subsidies are insufficient and result in no significant impact on general health knowledge. This paper also discusses certain restrictions that prevent general health knowledge from having an effect on toilet renovation. The article finally proposes policy recommendations for rural areas in China to better promote the rural toilet revolution and our results can also provide useful guidelines for drawing up relevant policies in other developing countries.
\end{abstract}

npj Clean Water (2021)4:21; https://doi.org/10.1038/s41545-021-00111-8

\section{INTRODUCTION}

General health knowledge (GHK) is arguably one of the main inputs in the production of health outcomes ${ }^{1}$. Education can help promote GHK by producing it either directly (as part of the school curriculum) or indirectly ("learning to learn," including, for example, being able to read public health messages) ${ }^{2}$. In developing countries, however, education is significantly weaker in rural areas than in urban areas. Therefore, rural residents may be unable to obtain GHK in the first place.

GHK is intimately linked to a number of Sustainable Development Goals (SDGs) that were adopted by all United Nations Member States in 2015, especially the SDGs for goal number 6, namely, to "Ensure availability and sustainable management of sanitation and water for all people, in all settings." More specifically, SDG 6.2 is to achieve access to adequate and equitable sanitation and hygiene for all by $2030^{3}$. The usage of improved toilet facilities is one of the key stepping stones towards the achievement of the SDG 6. However, today, 4.2 billion people live without safely managed sanitation, 673 million still practice open defecation and 3 billion lack basic handwashing facilities ${ }^{4}$. This situation is even more severe in developing countries, especially among residents of rural and lower-income areas ${ }^{5,6}$. About $50 \%$ of people living in rural areas lack improved sanitation facilities, compared to only $18 \%$ of people in urban areas ${ }^{7}$. Poor sanitation around the world results in increased prevalence of disease and increased environmental pollution ${ }^{8,9}$. Unsanitary toilets are recognized worldwide as a threat to ground water and public health ${ }^{10}$. Previous studies have confirmed that poor toilet conditions are linked to increased prevalence of diarrhea ${ }^{11}$, and that household access to improved toilets is often associated with reduced stunting risk ${ }^{12}$. Excreta, gray water and solid waste are major contributors to pollution that pose a risk to public health ${ }^{13}$.

Public agencies often grapple with the question of why the adoption of improved sanitation technologies has been slow ${ }^{14}$.
Many studies on factors that influence sanitation facility access have been conducted in developing countries. A review of the existing literature indicates that there is a relationship between access to different types of sanitation facilities and educational attainment, income/wealth, age, gender, household size, housing conditions, social norms, and geographic factors ${ }^{5,15-20}$. Although GHK is a complex policy-relevant issue, to date, the relationship between GHK and sanitation facility access has received little attention. In response to this issue, this study examines associations between GHK and sanitation facility access. In our conceptualization of sanitation facility access, we rely on toilet type, namely, flush toilet and non-flush toilet. We further investigate the relationship between three aspects of GHK and the use of flush toilets. Finally, we investigate the role of outside work experience and government subsidies, which are all special circumstances in China.

Our study makes two key contributions to the research on sanitation facility use. First, this paper provides a new theoretical perspective for the study of the use of health facilities. This paper uses field survey data to measure the GHK of farmers from diet, lifestyle, and medical treatment perspectives and studies the influence of GHK on the choice of sanitary toilets (flush toilets) by farmers. At the same time, the influence of GHK on the continuous use time of farmers' traditional latrine pits was analyzed using Duration Analysis. Second, the conclusions of this paper can provide policy reference for rural areas in China to solve the problem of poor sanitation and better promote the rural toilet revolution. Furthermore, our results can provide useful guidelines for drawing up relevant policies in other developing countries.

In Chinese rural areas, lack of sanitary toilet facilities has been the main cause of bad odor and disease spread ${ }^{7}$. Rural toilet work has always been valued by the state. In 1996, China first included toilet improvement in rural areas in its "Ninth Five-Year Plan," and it has been an important part of every 5-year plan since then. In addition, the "National Key Endemic Disease Prevention and

\footnotetext{
${ }^{1}$ College of Economics and Management, Shenyang Agricultural University, Shenyang, Liaoning, China. ${ }^{凶}$ email: zhoumi2011@syau.edu.cn
} 
Table 1. Regression coefficient results in Logit, Duration Analysis, and Spatial Autoregressive Model.

\begin{tabular}{|c|c|c|c|}
\hline & $\alpha$ (Eq. 1) & $\beta$ (Eq. 2) & $\eta($ Eq. 3) \\
\hline Spatial autoregressive coefficient: $\boldsymbol{\lambda}$ & & & $\begin{array}{l}0.070^{* * *} \\
(0.027)\end{array}$ \\
\hline Diet knowledge & $\begin{array}{c}0.340^{*} \\
(0.207)\end{array}$ & $\begin{array}{c}-0.486^{* *} \\
(0.230)\end{array}$ & $\begin{array}{c}0.080 \\
(0.306)\end{array}$ \\
\hline Lifestyle knowledge & $\begin{array}{l}0.911^{* * *} \\
(0.221)\end{array}$ & $\begin{array}{c}-1.022^{* * *} \\
(0.241)\end{array}$ & $\begin{array}{c}0.225 \\
(0.252)\end{array}$ \\
\hline Medical treatment knowledge & $\begin{array}{c}0.542^{*} \\
(0.279)\end{array}$ & $\begin{array}{c}-0.697^{* *} \\
(0.319)\end{array}$ & $\begin{array}{c}0.376 \\
(0.273)\end{array}$ \\
\hline Household head & $\begin{array}{c}-0.248 \\
(0.342)\end{array}$ & $\begin{array}{c}0.221 \\
(0.381)\end{array}$ & $\begin{array}{r}-0.367 \\
(0.557)\end{array}$ \\
\hline Gender & $\begin{array}{c}-0.179 \\
(0.352)\end{array}$ & $\begin{array}{c}0.213 \\
(0.390)\end{array}$ & $\begin{array}{c}0.592 \\
(0.444)\end{array}$ \\
\hline Age & $\begin{array}{c}0.017 \\
(0.013)\end{array}$ & $\begin{array}{c}0.002 \\
(0.014)\end{array}$ & $\begin{array}{c}0.004 \\
(0.014)\end{array}$ \\
\hline Marital status & $\begin{array}{c}-0.113 \\
(0.407)\end{array}$ & $\begin{array}{c}0.018 \\
(0.420)\end{array}$ & $\begin{array}{r}-0.032 \\
(0.556)\end{array}$ \\
\hline Highest education level & $\begin{array}{c}0.299^{*} \\
(0.158)\end{array}$ & $\begin{array}{c}-0.276 \\
(0.173)\end{array}$ & $\begin{array}{c}-0.031 \\
(0.182)\end{array}$ \\
\hline Health status & $\begin{array}{c}0.147 \\
(0.116)\end{array}$ & $\begin{array}{c}-0.031 \\
(0.134)\end{array}$ & $\begin{array}{c}0.023 \\
(0.158)\end{array}$ \\
\hline Village cadre & $\begin{array}{c}0.373 \\
(0.274)\end{array}$ & $\begin{array}{r}-0.398 \\
(0.287)\end{array}$ & $\begin{array}{l}0.593^{* *} \\
(0.287)\end{array}$ \\
\hline Working experience & $\begin{array}{l}0.621^{* * *} \\
(0.208)\end{array}$ & $\begin{array}{c}-0.694^{* * *} \\
(0.254)\end{array}$ & $\begin{array}{c}0.194 \\
(0.249)\end{array}$ \\
\hline Household size & $\begin{array}{c}0.150^{*} \\
(0.080)\end{array}$ & $\begin{array}{r}-0.155^{*} \\
(0.089)\end{array}$ & $\begin{array}{c}0.100 \\
(0.099)\end{array}$ \\
\hline Family income & $\begin{array}{c}0.135 \\
(0.108)\end{array}$ & $\begin{array}{c}-0.101 \\
(0.116)\end{array}$ & $\begin{array}{r}-0.037 \\
(0.101)\end{array}$ \\
\hline Frequency of yard cleaning & $\begin{array}{c}-0.065 \\
(0.044)\end{array}$ & $\begin{array}{l}0.135^{* * *} \\
(0.049)\end{array}$ & $\begin{array}{r}-0.054 \\
(0.038)\end{array}$ \\
\hline Water supply assurance rate & $\begin{array}{l}0.208^{* * *} \\
(0.076)\end{array}$ & $\begin{array}{c}-0.313^{* * *} \\
(0.095)\end{array}$ & $\begin{array}{r}-0.028 \\
(0.046)\end{array}$ \\
\hline Water fee paid & $\begin{array}{l}0.529^{* *} \\
(0.251)\end{array}$ & $\begin{array}{c}-0.957^{* * *} \\
(0.318)\end{array}$ & $\begin{array}{r}-0.017 \\
(0.100)\end{array}$ \\
\hline Poor family & $\begin{array}{l}0.848^{*} \\
(0.497)\end{array}$ & $\begin{array}{c}-1.253^{* *} \\
(0.622)\end{array}$ & $\begin{array}{c}0.087 \\
(0.572)\end{array}$ \\
\hline Village income & $\begin{array}{l}1.300^{* * *} \\
(0.502)\end{array}$ & $\begin{array}{c}-1.461^{* * *} \\
(0.482)\end{array}$ & $\begin{array}{c}0.170 \\
(0.131)\end{array}$ \\
\hline Toilet renovation project & $\begin{array}{c}-0.233 \\
(0.260)\end{array}$ & $\begin{array}{c}0.119 \\
(0.277)\end{array}$ & $\begin{array}{c}0.129 \\
(0.109)\end{array}$ \\
\hline Proportion of flushing toilets & $\begin{array}{l}0.018^{* * *} \\
(0.003)\end{array}$ & $\begin{array}{c}-0.022^{* * *} \\
(0.004)\end{array}$ & $\begin{array}{c}0.001 \\
(0.001)\end{array}$ \\
\hline Sanitation competition activities & $\begin{array}{c}0.065 \\
(0.248)\end{array}$ & $\begin{array}{c}0.001 \\
(0.300)\end{array}$ & $\begin{array}{c}0.056 \\
(0.091)\end{array}$ \\
\hline Poor village & $\begin{array}{c}-0.795^{* *} \\
(0.388)\end{array}$ & $\begin{array}{l}1.180^{* * *} \\
(0.431)\end{array}$ & $\begin{array}{r}-0.038 \\
(0.116)\end{array}$ \\
\hline $\begin{array}{l}\text { Average maximum temperature } \\
\text { in summer }\end{array}$ & $\begin{array}{r}-0.032 \\
(0.152)\end{array}$ & $\begin{array}{r}-0.012 \\
(0.191)\end{array}$ & $\begin{array}{r}-0.026 \\
(0.047)\end{array}$ \\
\hline Average minimum temperature in winter & $\begin{array}{c}0.030 \\
(0.042)\end{array}$ & $\begin{array}{r}-0.020 \\
(0.050)\end{array}$ & $\begin{array}{r}-0.001 \\
(0.018)\end{array}$ \\
\hline County fixed effect & YES & YES & NO \\
\hline Constant & $\begin{array}{c}-18.520^{* * *} \\
(5.315)\end{array}$ & $\begin{array}{l}23.820^{* * *} \\
(6.296)\end{array}$ & $\begin{array}{r}-1.229 \\
(2.074)\end{array}$ \\
\hline Observations & 1175 & 1175 & 106 \\
\hline R-squared & 0.360 & & \\
\hline
\end{tabular}

The reported statistics have standard errors shown in parentheses. The GS2SLS method is adopted in the regression of Eq. 3 and the heteroscedastic option is added to solve the heteroscedasticity problem. $* * * * * *$ Statistically significant at the $1 \% / 5 \% / 10 \%$ level.
Control Plan 2004-2010," "National Environment and Health Action Plan 2007-2015," and "The 11th Five-Year Plan for The Development of Health" also reflect the importance of toilet work. With the support of national policies and financial investment, China had made great progress in toilet retrofitting in rural areas $^{21}$. Since 2004, the central government has renovated 21.03 million rural toilets ${ }^{7}$. However, according to the results of the third national agricultural census published by the National Bureau of Statistics of China, there were 230 million sanitary toilets in rural areas in 2016, accounting for only $48.6 \%$ of toilets. Meanwhile, the potential environmental hazards of fecal sludge in China are still serious. The goal for rural toilet retrofitting in China is to reach the $100 \%$ sanitary toilet coverage rate by $2030^{22}$. Another 110 million toilets need to be built and therefore there is still room for significant further development. Understanding better what determines toilet retrofitting action in the context of the government's vigorous promotion of the toilet revolution in China therefore seems to be an environmental and health issue of utmost policy relevance.

\section{RESULTS}

\section{Regression analysis}

Table 1 lists the key regression results. The Logit Regression model (first column of Table 1) indicates that all three aspects of GHK have a positive association with flush toilet use. Therefore, the more GHK farmers have, the more they will emphasize the importance of sanitation, therefore they would prefer to use flush toilets. Some control variables also provided valuable information. Village wealth was significantly positively correlated with whether respondents used flush toilets. The probability that respondents used flush toilets was higher in areas with high water supply assurance rate. Therefore, the use of flush toilets is both dependent on personal insight and limited by sanitation infrastructure. The parameters of other control variables are generally similar to those in previous research about sanitation facility use.

Model 2 (second column of Table 1) shows the influence of GHK on the average duration of farmer traditional latrine pit use. The Duration Analysis results show that all three aspects of GHK have significant negative associations with the average duration of traditional latrine pit use. Traditional latrine pits have a heavier odor than flush toilets and are breeding grounds for mosquitoes and flies. The more GHK the farmers have, the sooner they will start to use flush toilets. In addition to GHK, toilet renovation is also affected by socioeconomic status, infrastructure, and other factors. The results of Model 2 show that the higher the farmers' income is, the better their water supply facilities are, the sooner it is for them to start using flush toilets.

Model 3 (third column of Table 1) shows the regression outcomes found using the Spatial Autoregressive Model. The value of $\boldsymbol{\lambda}$ in Table 1 is the result of the spatial autoregressive coefficient, which indicates that the use of flush toilets in other villages in the same county has a significant positive correlation with the use of flush toilets in a given village. That is, there is a learning effect. It shows that the use of flush toilets in adjacent villages promotes the use of toilets in this village.

To illustrate the significance of our findings, we generated marginal effect plots based on the effect of GHK on toilet renovation. These plots are significant at the 0.01 level. Figure 1 is based on Model 1 in Table 1. The predicted value of 0 on the $Y$ axis means that a given region uses traditional latrine pits; the value of 100 means that a region uses flush toilets. When we change diet knowledge (Fig. 1a) from 0 to 1 , predicted flush toilet use rises from 16.6 to $19.7 \%$. Similarly, when we change lifestyle knowledge (Fig. 1b) and medical treatment knowledge (Fig. 1c) from 0 to 1, predicted flush toilet use rises from 15.3 to $24.4 \%$ and from 14.2 to 
Predictive Margins with $95 \% \mathrm{Cls}$
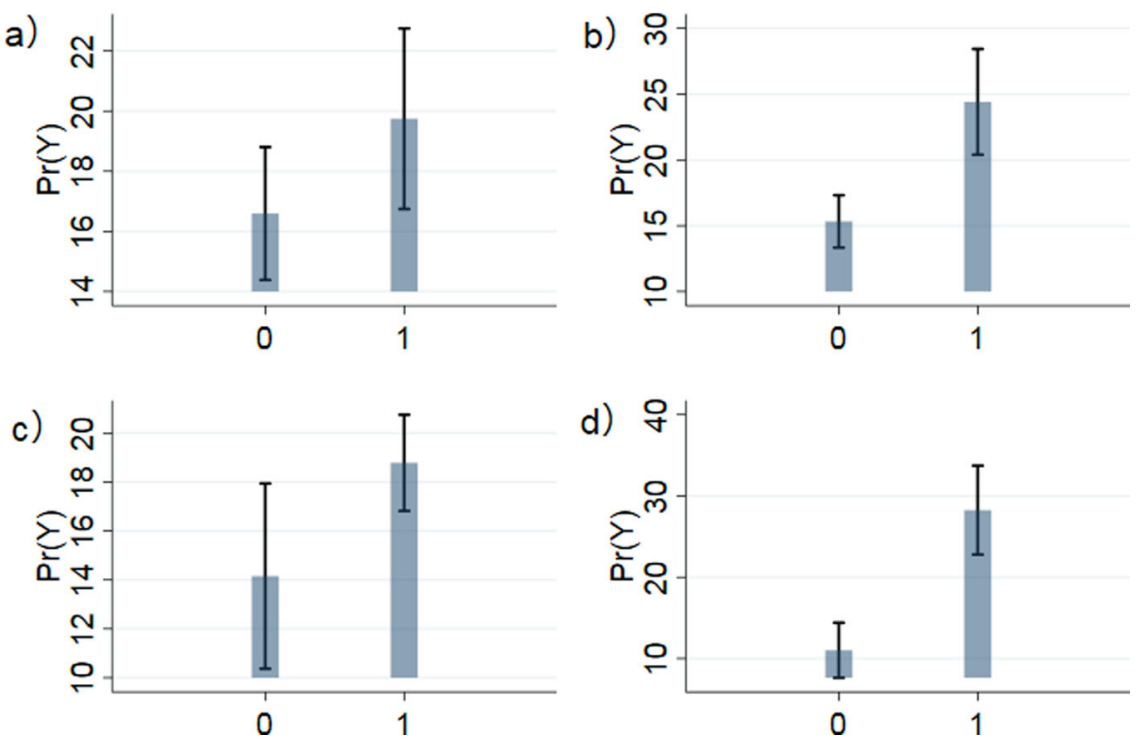

Fig. 1 Marginal effects of diet knowledge, lifestyle knowledge, and medical treatment knowledge on flush toilet use (based on Model 1 in Table 1). Marginal effect of diet knowledge (a), lifestyle knowledge (b), medical treatment knowledge (c), and all three aspects of GHK (d) on flush toilet use. The line segment is a $95 \%$ confidence interval.

$18.8 \%$, respectively. The shift of all three aspects of GHK from 0 to 1 (Fig. 1d) leads to a rise in predicted flush toilet use from 11.0 to 28.3\%. Together, these predictions use plots to highlight the implications of our statistical results.

\section{Heterogeneity analysis}

In China, migrant workers are defined as people who move from Chinese rural areas to cities in other parts of the country to engage in non-agricultural work ${ }^{23}$. In our sample, 904 households had members who had taken on non-agricultural work in other cities. These people had lived in the city for a long time and had therefore used city sanitation facilities. Therefore, they had gotten used to using flush toilets and realized that flush toilets were convenient, comfortable, safe, and hygienic. It can be seen from Table 2 that the effects of GHK remained positive and statistically significant in the group with work experience. For the group without work experience, the effect was not significant.

Table 2 also presents the results of grouped regressions by government subsidies. Based on the results, GHK had a significant effect on those without government subsidies but not on those with government subsidies, suggesting that government subsidies have little impact on the use of flush toilets by farmers. We believe this may be because the small income from government subsidies did not inspire farmers to switch to flush toilets. The average amount respondents receive from government subsidies is 759 yuan, and the minimum is only 100 yuan, which is clearly not enough to cover the costs of toilet renovation. Moreover, subsidies do not help solve another problem-the management and maintenance of flush toilets. The financial capital input only subsidizes part of the construction costs, and the costs for later management and maintenance need to be borne by the farmers and their villages. Therefore, some families prefer to keep their traditional latrine pits because they cannot pay or are unwilling to pay the related fees.

In addition, some areas did not provide corresponding supporting facilities during toilet renovation, and due to the lack of rural sewage pipeline systems, many farmers gave up on the use of new toilets and switched to traditional latrine pits. The results based on grouped regressions by non-stop water supply suggest the importance of sanitation infrastructure in rural areas. It can be seen that the effects of GHK were positive and statistically significant in the group with non-stop water supply. However, for the group without non-stop water supply, the impact of GHK was not significant, indicating that imperfect infrastructure will also affect the use of flush toilets by farmers.

\section{DISCUSSION}

Our study showed that GHK had a significant positive association with flush toilet use and a significant negative association with the average duration of traditional latrine pits use. Our results highlight the fact that the effect of GHK may be limited by a number of conditions. This means that, even if farmers have certain GHK, they will choose to use non-flush toilets due to income and infrastructure constraints.

First, as many studies have shown, economic status is a major determinant of sanitation improvement, and poverty is significantly correlated with the use of unimproved facilities or open defecation. For example, the likelihood of using improved sanitation facilities was more than twice as high in higherincome households than in lower-income households in rural Ethiopia and Tanzania ${ }^{24,25}$. Our study reached the same conclusion.

Rural residents need to use a certain proportion of their own money for toilet renovation (the proportion of their own money is different in different provinces and cities across the country), thus increasing rural resident health expenditure. At the same time, after the completion of sanitation infrastructure construction, the annual maintenance cost in the later stage increases the economic burden on farmers. This means that, even if farmers have GHK, income restrictions may cause them not to improve their sanitation facilities.

Second, due to quality issues, the newly built sanitary toilets often encountered problems that stopped them from being used later. The Chinese government has supported the renovation of rural toilets for nearly 30 years and has invested a lot of resources every year. Although statistics show that sanitary toilets are becoming more common in China, the usage rate of sanitary 
Table 2. Heterogeneity analysis results.

\begin{tabular}{|c|c|c|c|}
\hline $\begin{array}{l}\text { Dependent } \\
\text { variable: } \\
\text { flush toilet }\end{array}$ & $\begin{array}{l}\text { (1) } \\
\text { Diet } \\
\text { knowledge }\end{array}$ & $\begin{array}{l}\text { (2) } \\
\text { Lifestyle } \\
\text { knowledge }\end{array}$ & $\begin{array}{l}\text { (3) } \\
\text { Medical } \\
\text { treatment } \\
\text { knowledge }\end{array}$ \\
\hline \multicolumn{4}{|c|}{ Working experience } \\
\hline YES $n=904$ & $\begin{array}{c}0.401^{*} \\
(0.222)\end{array}$ & $\begin{array}{l}0.892^{* * *} \\
(0.237)\end{array}$ & $\begin{array}{l}0.683^{* *} \\
(0.306)\end{array}$ \\
\hline NO $n=271$ & $\begin{array}{c}0.791 \\
(0.843)\end{array}$ & $\begin{array}{l}1.526^{*} \\
(0.852)\end{array}$ & $\begin{array}{r}-0.437 \\
(0.908)\end{array}$ \\
\hline \multicolumn{4}{|c|}{ Government subsidies } \\
\hline YES $n=119$ & $\begin{array}{r}-1.271 \\
(0.938)\end{array}$ & $\begin{array}{l}3.881^{* * *} \\
(1.496)\end{array}$ & $\begin{array}{r}-1.580 \\
(1.336)\end{array}$ \\
\hline NO $n=1056$ & $\begin{array}{l}0.516^{* *} \\
(0.229)\end{array}$ & $\begin{array}{l}0.990^{* * *} \\
(0.240)\end{array}$ & $\begin{array}{l}0.721^{* *} \\
(0.324)\end{array}$ \\
\hline \multicolumn{4}{|c|}{ Non-stop water supply } \\
\hline YES $n=917$ & $\begin{array}{c}0.326 \\
(0.228)\end{array}$ & $\begin{array}{l}0.915^{* * *} \\
(0.244)\end{array}$ & $\begin{array}{l}0.730^{* * *} \\
(0.306)\end{array}$ \\
\hline NO $n=258$ & $\begin{array}{c}0.335 \\
(0.498)\end{array}$ & $\begin{array}{c}0.900 \\
(0.554)\end{array}$ & $\begin{array}{c}0.093 \\
(0.661)\end{array}$ \\
\hline \multicolumn{4}{|c|}{ There are village cadres at home } \\
\hline YES $n=249$ & $\begin{array}{l}1.016^{* *} \\
(0.425)\end{array}$ & $\begin{array}{c}0.473 \\
(0.482)\end{array}$ & $\begin{array}{r}-0.543 \\
(0.573)\end{array}$ \\
\hline NO $n=926$ & $\begin{array}{c}0.157 \\
(0.250)\end{array}$ & $\begin{array}{l}1.150^{* * * *} \\
(0.266)\end{array}$ & $\begin{array}{l}0.966^{* * *} \\
(0.353)\end{array}$ \\
\hline \multicolumn{4}{|c|}{ There are children at home } \\
\hline YES $n=291$ & $\begin{array}{l}1.141^{* * *} \\
(0.431)\end{array}$ & $\begin{array}{l}1.239^{* * * *} \\
(0.411)\end{array}$ & $\begin{array}{r}-0.191 \\
(0.520)\end{array}$ \\
\hline NO $n=884$ & $\begin{array}{c}0.098 \\
(0.257)\end{array}$ & $\begin{array}{l}0.811^{* * *} \\
(0.287)\end{array}$ & $\begin{array}{l}1.141^{* * *} \\
(0.377)\end{array}$ \\
\hline \multicolumn{4}{|l|}{ Age } \\
\hline Youth $n=139$ & $\begin{array}{c}0.881 \\
(0.756)\end{array}$ & $\begin{array}{l}3.445^{* * *} \\
(0.959)\end{array}$ & $\begin{array}{r}-0.394 \\
(1.214)\end{array}$ \\
\hline $\begin{array}{l}\text { Middle age } \\
n=560\end{array}$ & $\begin{array}{c}0.602^{*} \\
(0.311)\end{array}$ & $\begin{array}{c}0.508 \\
(0.318)\end{array}$ & $\begin{array}{l}1.456^{* * *} \\
(0.507)\end{array}$ \\
\hline $\begin{array}{l}\text { Elderly age } \\
n=476\end{array}$ & $\begin{array}{r}-0.182 \\
(0.424)\end{array}$ & $\begin{array}{l}0.986^{* *} \\
(0.465)\end{array}$ & $\begin{array}{c}0.008 \\
(0.464)\end{array}$ \\
\hline Control variable & YES & YES & YES \\
\hline $\begin{array}{l}\text { County } \\
\text { fixed effect }\end{array}$ & YES & YES & YES \\
\hline
\end{tabular}

The reported statistics have standard errors shown in parentheses. Control variable: household head, gender, age, marital status, highest education level, health status, village cadre, working experience, household size, family income, frequency of yard cleaning, water supply assurance rate, water fee paid, poor family, village income, toilet renovation project, proportion of flushing toilets, sanitation competition activities, poor village, average maximum temperature in summer, average minimum temperature in winter. According to the age classification standard of the World Health Organization, youth is set to be aged $\leq 44$ years, middle age is $45-59$ years, and elderly is $\geq 60$ years.

$* * * / * * *$ Statistically significant at the $1 \% / 5 \% / 10 \%$ level.

toilets is still low. In the field investigation, we found that many sanitary toilets were almost abandoned. When asked why they were not used, the answer was that the toilet facilities were easily damaged and could no longer be used, so they turned to the original non-sanitary toilets. Further investigation revealed that toilet facilities were vulnerable to damage because of the use of cheap products in construction. In addition, as mentioned earlier, in areas with low temperatures in winter, the problem of freezing water pipes is common, so some farmers will abandon the use of newly renovated toilets.

Clearly, reconstruction of toilets in rural areas of China is currently a government action. When implementing toilet reform projects, various regions do not have a thorough understanding of what rural residents need for toilet reform. Additionally, if government support is insufficient, there will be a number of poor-quality sanitary toilets that cannot be used. This has led to many rural areas having two toilets in one household. Although the coverage rate of sanitary toilets is high, the actual utilization rate is low, resulting in insufficient use of government financial investment in improving toilets.

Our results have strong policy implications. First, rural populations in China are mostly made up of left-behind elderly people and children, who lack GHK. Policy makers should make full use of the press, radio, television, and other news media as well as new Internet media to strengthen health publicity and education of environmental health knowledge. In this way, they will promote awareness of environmental health and health habits and increase demand for environmental health services.

Second, one of the priorities for the next step of rural toilet reform should be maintenance and management of sanitary toilets. Rural toilet renovation is just the first step toward improving rural environmental sanitation facilities. Sanitary toilet maintenance is more important. In the field survey, we found that rural residents often fail to perform maintenance and management of toilets, causing problems such as waste-concentrated cleaning problems. Centralized disposal of feces is a government responsibility. To solve the issue of flush toilets freezing in winter, a deep fermentation tank can be built to give the septic tank an anti-freezing effect through the fermentation and decomposition of manure water. The toilet can also be installed above the septic tank, with the inlet pipe set vertically to avoid feces and urine freezing in the inlet pipe and the toilet ${ }^{26}$. In addition, due to differences in climate and economic development, toilets should be constructed according to the local rural geographical environment, population, and economic conditions. For example, in mountainous areas or areas where water is scarce, double-pit latrines can be used instead of flush toilets. To address the problem of manure disposal, village or townships can be equipped with suction trucks in order to avoid the direct discharge of manure into the surrounding environment, endangering the ecological environment and human health.

Finally, the economic burden placed on rural residents during the process of toilet renovation should be reduced. In order to meet this goal, the state finance should give larger subsidies to rural residents. At the same time, the government should focus on increasing coverage of the maintenance cost after the construction of sanitary toilets, for example, by issuing a yearly subsidy for the maintenance of infrastructure so as to gradually relieve the economic stress caused by the construction of sanitary infrastructure for rural residents. Additionally, due to the large consumption of funds for rural toilet construction or renovation projects, it is also necessary to actively broaden financing channels for toilet renovation and encourage enterprises and social welfare organizations to use donations to make financing investments.

Our study faces some limitations. First, due to the crosssectional and non-experimental nature of our data, we are unable to make causal claims in our analysis. Another limitation is that our findings rely on survey data that may be prone to measurement and reporting errors. Finally, our sample is restricted to a province in China. Nevertheless, we believe that the sample is representative and well suited to test our theoretical predictions and represents an interesting case for the analysis of the input-output mechanism in a low-income setting. Further research using more representative data from different countries and regions is needed 
to test whether the reported relationships hold in other settings and to further improve our understanding of determinants of health decisions in developing countries.

\section{METHODS Study design}

This study was conducted in Liaoning province in northeast China. The district lies between latitude $38^{\circ} 43^{\prime} \mathrm{N}-43^{\circ} 26^{\prime} \mathrm{N}$ and longitude $118^{\circ} 53^{\prime} \mathrm{E}-125^{\circ}$ $46^{\prime} \mathrm{E}$. Liaoning province has a total land area of $148,000 \mathrm{~km}^{2}$ and a resident population of 43.593 million. The rural population is 13.906 million, accounting for $31.9 \%$ of the total population. The region has a temperate continental monsoon climate with four distinct seasons. Winter is long and cold, summer is hot and rainy, spring is less rainy and windy, and autumn is short and sunny. The annual average temperature is $5.2-11.7^{\circ} \mathrm{C}$, the highest temperature is around $30^{\circ} \mathrm{C}$, and the lowest temperature is around $-30^{\circ} \mathrm{C}$. The average annual precipitation is $400-970 \mathrm{~mm}$.

Data were collected using in-person interviews of rural households in Liaoning Province, China in December 2018. The data collection was completed by Shenyang Agricultural University, Peking University, Liaoning University, and Shenyang University of Technology. The authors of this article are mainly responsible for the questionnaire design and data survey. In the survey, we adopted a stratified random sampling methodProbability-Proportional-to-Size Sampling (PPS). The sampling followed standard sampling practices. The specific sampling process is as follows: (1) The first step is to determine the sample county (district, county-level city). Based on 2017 per capita GDP, counties (districts, county-level cities) were divided into three categories: high, medium, and low. In each category, 4 counties (districts, county-level cities) were randomly selected for a total of 12 sample counties (districts, county-level cities). (2) After the sample counties (districts, county-level cities) were determined, the same method of stratified random sampling was used to extract 3 sample towns in each sample county (districts, county-level cities) for a total of 36 sample towns. (3) By means of random sampling, 106 villages were selected from sample towns. (4) One thousand one hundred and eighty households were randomly selected from the 106 villages. Our investigators asked respondents to answer every question in the questionnaire. After eliminating the incomplete questionnaires, a total of 1175 valid questionnaires were obtained.

\section{Variable selection}

The dependent variable in this study was toilet type. The household-level survey question is: What type of toilet is your family using now? Of the 1175 households surveyed, 210 households used flush toilets, accounting for $17.9 \%$ of the total, while the remaining 965 households still used traditional latrine pits (see Supplementary Fig. 1).

We measured the respondents' GHK from three perspectives: dietary habits, lifestyle habits, and medical treatment habits. We used the following three questions to measure these areas: "Do you often cook extra food and then keep it to heat up for the next meal?" "Do you bathe more than twice a week in winter?," and "Does your family choose being directly infused by an intravenous drip after catching a cold?" For the first and third questions, we coded one if NO and zero otherwise. On the second question, we coded one if YES and zero otherwise. From the $T$ test results in Table 3, it can be seen that there are significant differences in the three aspects of GHK between respondents who use flush toilets and nonflush toilets. Respondents who used flush toilets had significantly higher GHK than those who used traditional latrine pits.

Control variables for individual characteristics include gender, age, marital status, educational attainment, health, and working experience. Health is the self-rated health status of the respondents. The sample farmers are mostly male, with an average age of nearly 57 years, and are, on average, "relatively healthy" (Supplementary Table 1). Work experience refers to whether the respondent has engaged in non-agricultural work in or before 2018. Existing research indicates that educational attainment is one of the factors that influences household sanitation facilities. In our research (see Table 3), we find that respondents with higher educational entertainment were more likely to use flush toilets. This finding is consistent with the existing research ${ }^{5,15-17}$. In addition, respondents who have left their hometown to pursue non-agricultural work use flush toilets more than those who have not. Rural laborers usually work in more developed cities and have experience using flush toilets in cities, which gives them more willingness to use flush toilets after returning to rural areas. Existing research has confirmed that visiting better latrines elsewhere was a commonly reported reason for improving latrines ${ }^{27}$. In addition, we also included some characteristics that reflect the role of individual demonstration, such as whether the interviewees are village cadres.

Control variables for household characteristics include household size (Family size), family annual per-capita income, the frequency of yard cleaning, water supply assurance rate, whether they pay a water fee (yes or no), and if they are a poor family or not. Existing research also indicates that family size plays an important role in influencing improved sanitation. Adams et al. finds that larger households tend to have better access to improved sanitation facilities ${ }^{15}$. A number of studies also revealed that economic status is a major determinant of sanitation improvement ${ }^{16,18,28}$. As can be seen in Table 3, both family size and family income have a significant positive correlation with flush toilets. Respondents from poor family were more likely to use non-flush toilets.

Control variables for village characteristics include village annual percapita net income, whether the village has implemented toilet construction or renovation projects (yes or no), the proportion of flush toilets used in the village, whether the village has conducted a family health evaluation program (yes or no), and whether it is a poor village or not. In rural China, government programs and policies, such as financial support, play a very important role in sanitation improvement ${ }^{29}$. From the survey results, only 119 households in the sample have government subsidies, accounting for $10 \%$ of the total sample. However, if the village where the respondent is located is a wealthier village, in general, it will use part of its income for the construction or reconstruction of sanitary toilets. We found that village income has a significant positive correlation with flush toilets. Respondents from poor villages were more likely to use non-flush toilets.

Studies also point to environmental factors as determinants of toilet use. Temperature plays a role in household toilet type: the likelihood of always/ usually versus never using the latrine was significantly greater in the dry cold season ${ }^{30}$. At the same time, during times of drought, people increasingly use pit latrines rather than flush toilets ${ }^{31}$. In our study, we use a measure of average maximum temperature in summer and average minimum temperature in winter (in ${ }^{\circ} \mathrm{C}$ ), respectively, to control for toilet use. In our sample areas with lower temperatures, newly built outdoor flush toilets may become "ice toilets" due to low temperatures and become unusable, so the farmers have to use their original latrine pits. Our results show that households in areas with lower average winter temperatures were more likely to use non-flush toilets.

\section{Econometric modeling}

First, a Logit Regression was used to empirically analyze the impact GHK had on whether respondents used flush toilets ${ }^{32}$. The specific model is as follows:

$$
\mathbf{y}=\mathbf{X a}+\boldsymbol{\varepsilon}
$$

In formula (1), $\mathbf{y}$ is the dependent variable, indicating whether the respondents use flush toilets; $\mathbf{X}$ is the explanatory variable, which refers to three aspects of GHK and other control variables, including individual, family, village characteristics, and physical environment; $\boldsymbol{\alpha}$ is the coefficient to be evaluated; and $\boldsymbol{\varepsilon}$ is the random disturbance term.

In order to investigate the impact of GHK on the duration of traditional latrine pits use of the respondents, we investigated and calculated the time respondent families spent using traditional latrine pits and using flush toilets and conducted an empirical study using Duration Analysis. A wellused model for adjusting survival functions for the effects of covariates is the Accelerated Failure-Time Model. According to Cameron and Trival ${ }^{33}$, from the perspective of econometrics, the Accelerated Failure-Time Model mainly studies the amount of time spent shifting from one state to another. In the Accelerated Failure-Time Model, the natural logarithm of the survival time is defined as a linear function of the covariates. The specific model is as follows:

$$
\ln T_{\mathbf{i}}=\mathbf{x}_{\mathbf{i}}^{\prime} \boldsymbol{\beta}+\boldsymbol{\mu}_{\mathbf{i}}
$$

$\mathbf{T}_{\mathbf{i}}= \begin{cases}2018-\mathbf{t}_{\mathbf{h}}, & \text { if } \mathbf{t}_{\mathbf{h}}=\mathbf{t}_{\mathbf{l c}} \\ \mathbf{t}_{\mathrm{cc}}-\mathbf{t}_{\mathbf{h}}, & \text { if } \mathbf{t}_{\mathbf{h}} \leq \mathbf{t}_{\mathrm{cc}} \\ \mathbf{t}_{\mathrm{ct}}-\mathbf{t}_{\mathbf{h}}, & \text { if } \mathbf{t}_{\mathbf{h}} \leq \mathbf{t}_{\mathrm{ct}}\end{cases}$

$\mathbf{T}_{\mathbf{i}}$ is the length of time a latrine was used, $\mathbf{t}_{\mathbf{h}}$ is the time the house was built, $\mathbf{t}_{\mathbf{l c}}$ is the time the latrine was constructed, $\mathbf{t}_{\mathbf{c c}}$ is the time the flush toilet was constructed, and $\mathbf{t}_{\mathrm{ct}}$ is the time the flush toilet was transformed. 
L. Huang et al.

Table 3. $T$ test results between respondents who use flush toilets and non-flush toilets.

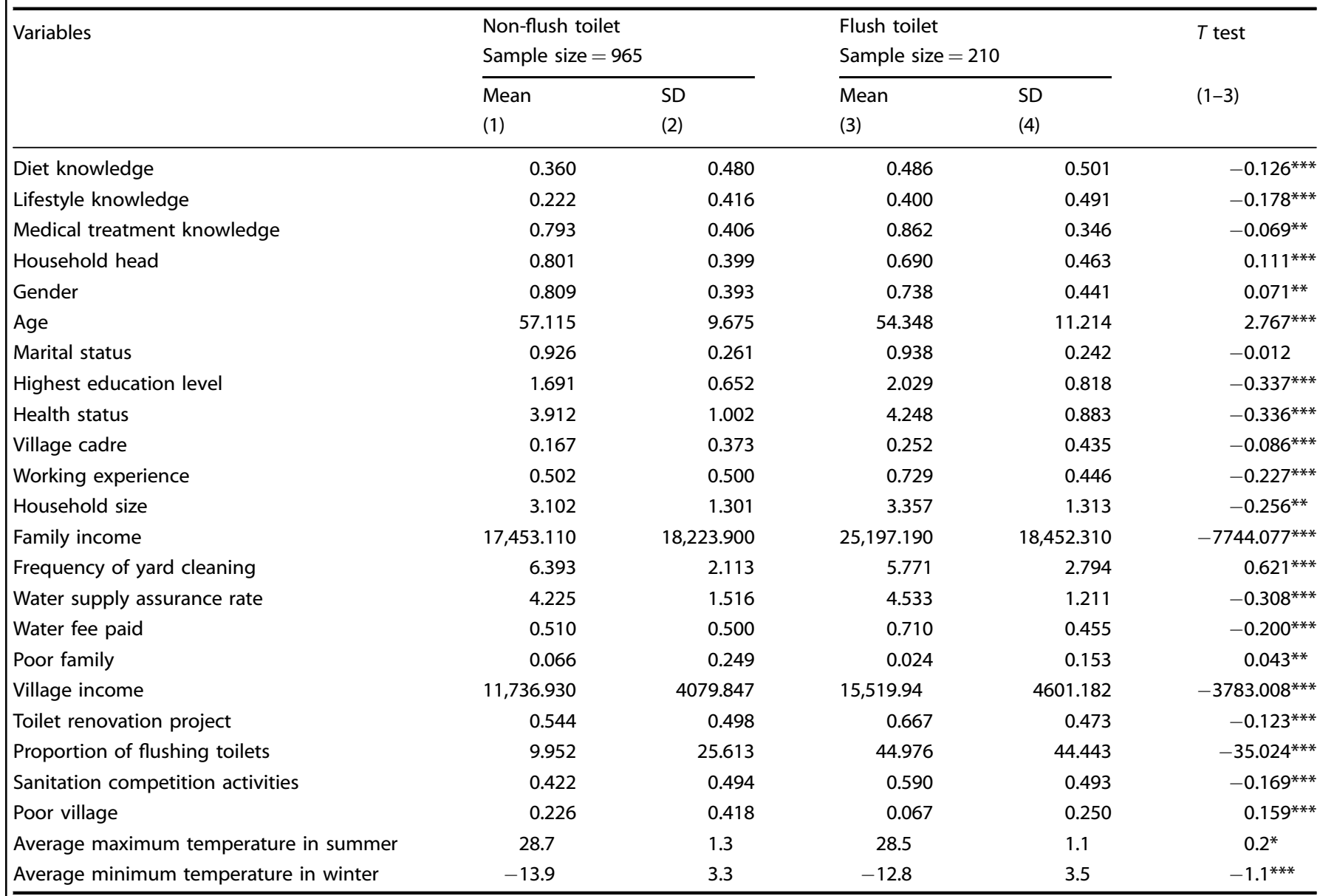

Summer: June-August, winter: December-February, according to http://www.cma.gov.cn/kppd/kppdqxwq/kppdjckp/201212/t20121211_195406.html.

$* * * * * * *$ Statistically significant at the $1 \% / 5 \% / 10 \%$ level.

If the construction time of the house is missing, the time of flush toilet reconstruction or construction is used instead. In addition, considering the nature of duration data (time $>0$ ), adjustments have been made to the duration of latrine use. The final value is equal to the duration of latrine use plus $1 . \mathbf{x}_{\mathbf{i}}$ is a series of explanatory variables, including three aspects of GHK and other control variables; $\boldsymbol{\beta}$ is the coefficient to be evaluated; and $\boldsymbol{\mu}_{\mathbf{i}}$ is the random disturbance term. The critical event of this model was the use of flush toilets by the respondents.

Finally, the Spatial Autoregressive Model is used to study the direct impact of flush toilet use in one area on flush toilet use in other areas ${ }^{32}$. The mathematical expression of the Spatial Autoregressive Model is as follows:

$$
\mathbf{y}=\mathbf{\lambda W y}+\mathbf{X n}+\boldsymbol{\mu}
$$

In the formula, $\mathbf{y}$ refers to whether there are households in village using flush toilets. If there are, the value is 1 ; otherwise, the value is $0 . \boldsymbol{\lambda}$ is the spatial autoregressive coefficient, which indicates the influence of the use of flush toilets in adjacent villages on the use of flush toilets in this village. $\mathbf{W}$ is the spatial weight matrix. $\mathbf{X}$ is the vector of explanatory variables; $\boldsymbol{\eta}$ is the regression coefficient vector of the explanatory variable $\mathbf{X} ; \boldsymbol{\mu}$ is the residual term. If the spatial autoregressive coefficient $\boldsymbol{\lambda}$ in the formula is significantly positive, it indicates that the use of flush toilets in other villages in the county has a positive impact on the use of flush toilets in this village and that there is a learning effect between villages.

\section{Ethics statement}

The study received ethical approval from the Shenyang Agricultural University Institutional Review Board, and all procedures performed in studies involving human participants were following the 1964 Helsinki Declaration and its later amendments. Informed consent was obtained from all of the participants of our study.

\section{DATA AVAILABILITY}

The data that support the findings of this study are available from Peking University but restrictions apply to the availability of these data, which were used under license for the current study, and so are not publicly available. Data are, however, available from the authors upon reasonable request and with permission of Peking University.

\section{CODE AVAILABILITY}

The code used for the analyses is available from the corresponding author upon request.

Received: 6 August 2020; Accepted: 12 January 2021;

Published online: 26 March 2021

\section{REFERENCES}

1. Blunch, N. H. \& Gupta, N. D. Mothers' health knowledge gap for children with diarrhea: a decomposition analysis across caste and religion in India. World Dev. 126, 104718 (2020).

2. Blunch, N. H. A teenager in love: multidimensional human capital and teenage pregnancy in Ghana. J. Dev. Stud. 54, 557-573 (2018).

3. UNICEF/WHO. Progress on Drinking Water, Sanitation and Hygiene: 2017 Update and SDG Baselines (World Health Organization, 2017). 
4. WHO/UNICEF. Joint Monitoring Programme 2019 update report: progress on household drinking water, sanitation and hygiene. https://www.who.int/ water_sanitation_health/publications/jmp-report-2019/en/ (2019).

5. Abubakar, I. R. Access to sanitation facilities among nigerian households: determinants and sustainability implications. Sustainability 9, 547 (2017).

6. Atuyambe, L. M., Ediau, M., Orach, C. G., Musenero, M. \& Bazeyo, W. Land slide disaster in eastern Uganda: rapid assessment of water, sanitation and hygiene situation in Bulucheke camp, Bududa district. Environ. Health 10, 38 (2011).

7. Cheng, S. K. et al. Toilet revolution in China. J. Environ. Manag. 216, 347-356 (2018).

8. UN MFA. Report on China's Implementation of the Millennium Development Goals (2000-2015), Beijing (UN MFA, 2015)

9. WHO UNICEF. Progress on Sanitation and Drinking Water: 2015 Update and MDG Assessment (UNICEF, 2015).

10. Wu, S. M., Li, H. M., Li, Q. \& Mi, L. Assessing willingness to pay for upgrading toilets in rural areas of Shaanxi and Inner Mongolia, China. Desalination Water Treat. 156, 106-115 (2019).

11. Denslow, S. A. et al. Improvements to water purification and sanitation infrastructure may reduce the diarrheal burden in a marginalized and flood prone population in remote Nicaragua. BMC Int. Health Hum. Rights 10, 30 (2010).

12. Dearden, K. A. et al. Children with access to improved sanitation but not improved water are at lower risk of stunting compared to children without access: a cohort study in Ethiopia, India, Peru, and Vietnam. BMC Public Health 17, 110 (2017)

13. Katukiza, A. Y. et al. Sustainable sanitation technology options for urban slums Biotechnol. Adv. 30, 964-978 (2012).

14. Seleman, A. \& Bhat, M. G. Multi-criteria assessment of sanitation technologies in rural Tanzania: implications for program implementation, health and socioeconomic improvements. Technol. Soc. 46, 70-79 (2016).

15. Adams, E. A., Boateng, G. O. \& Amoyaw, J. A. Socioeconomic and demographic predictors of potable water and sanitation access in Ghana. Soc. Indic. Res. 126, 673-687 (2016).

16. Cobbinah, P. B., Kosoe, E. A. \& Diawuo, F. Environmental planning crisis in urban Ghana: local responses to nature's call. Sci. Total Environ. 701, 134898 (2020).

17. Mosler, H. J., Mosch, S. \& Harter, M. Is community-led total sanitation connected to the rebuilding of latrines? Quantitative evidence from Mozambique. PLOS ONE 13, e0197483 (2018).

18. Munamati, M., Nhapi, I. \& Misi, S. N. Types and distribution of improved sanitation technologies in sub-Saharan Africa. J. Water Sanitation Hyg. Dev. 7, 260-271 (2017).

19. Hirai, M. et al. Determinants of toilet ownership among rural households in six eastern districts of Indonesia. J. Water Sanitation Hyg. Dev. 8, 533-545 (2018).

20. Novotny, J., Ficek, F., Hill, J. K. W. \& Kumar, A. Social determinants of environmental health: a case of sanitation in rural Jharkhand. Sci. Total Environ. 643 762-774 (2018)

21. NHFPC. China Health and Family Planning Statistical Yearbook (in Chinese) (Peking Union Medical College Press, 2016).

22. State Council. Health China 2030 Program Planning, Beijing (State Council, 2016).

23. Huang, L., Zhang, X., Zhou, M., Nuse, B. \& Tong, L. Y. Depressive symptoms and migrant worker wages: estimation based on a nationally-representative panel dataset. Int. J. Environ. Res. Public Health 16, 1009 (2019).

24. Yohannes, T., Workicho, A. \& Asefa, H. A. Cross sectional study: availability of improved sanitation facilities and associated factors among rural communities in Lemo Woreda, Hadiya Zone, Southern Ethiopia. Libr. J. 1, e1020 (2014).

25. Kema, K. et al. Factors affecting the utilisation of improved ventilated latrines among communities in Mtwara rural district, Tanzania. Pan Afr. Med. J. 13, 4 (2012)

26. Zhang, Y. et al. Functional orientation of three compartment septic tank toilet and its application errors in rural toilet improvement. J. Agric. Resour. Environ. https://doi.org/10.13254/j.jare.2020.0231 (2020).

27. Czerniewska, A., Muangi, W. C., Aunger, R., Massa, K. \& Curtis, V. Theory-driven formative research to inform the design of a national sanitation campaign in Tanzania. PLoS ONE 14, e0221445 (2019).
28. Whittington, D. et al. Household demand for improved sanitation services in Kumasi, Ghana-a contingent valuation study. Water Resour. Res. 29, 1539-1560 (1993).

29. Li, X. L. et al. Household access to sanitation facilities in rural China. J. Water Sanitation Hyg. Dev. 5, 465-473 (2015).

30. Sinha, A. et al. Assessing patterns and determinants of latrine use in rural settings: a longitudinal study in Odisha, India. Int. J. Hyg. Environ. Health 220, 906-915 (2017).

31. McGill, B. M. et al. Complex interactions between climate change, sanitation, and groundwater quality: a case study from Ramotswa, Botswana. Hydrogeol. J. 27, 997-1015 (2019).

32. Chen, Q. Advanced Econometrics and Stata Applications (Second Edition) (in Chinese) (Higher Education Press, 2014).

33. Cameron, A. C. \& Trivedi, P. K. Microeconometrics Methods and Applications (Cambriage University Press, 2005).

\section{ACKNOWLEDGEMENTS}

We would like to acknowledge the support from the National Natural Science Foundation of China (71973100, 71903133 and 71573179) and Research Project on Economic and Social Development of Liaoning Province (2021lsljdybkt-015, 2021lsljdzdkt-015).

\section{AUTHOR CONTRIBUTIONS}

M.Q.: data curation, methodology; M.Z.: conceptualization, writing-reviewing and editing; L.H.: conceptualization, writing-original draft.

\section{COMPETING INTERESTS}

The authors declare no competing interests.

\section{ADDITIONAL INFORMATION}

Supplementary information The online version contains supplementary material available at https://doi.org/10.1038/s41545-021-00111-8.

Correspondence and requests for materials should be addressed to M.Z.

Reprints and permission information is available at http://www.nature.com/ reprints

Publisher's note Springer Nature remains neutral with regard to jurisdictional claims in published maps and institutional affiliations.

Open Access This article is licensed under a Creative Common cc) Attribution 4.0 International License, which permits use, sharing, adaptation, distribution and reproduction in any medium or format, as long as you give appropriate credit to the original author(s) and the source, provide a link to the Creative Commons license, and indicate if changes were made. The images or other third party material in this article are included in the article's Creative Commons license, unless indicated otherwise in a credit line to the material. If material is not included in the article's Creative Commons license and your intended use is not permitted by statutory regulation or exceeds the permitted use, you will need to obtain permission directly from the copyright holder. To view a copy of this license, visit http://creativecommons. org/licenses/by/4.0/.

(c) The Author(s) 2021 